\title{
Enhanced Expression of BCL2/Adenovirus EIB 19-kDa-Interacting Protein 3 mRNA, a Candidate for Intrinsic Depression-Related Factor, and Effects of Imipramine in the Frontal Cortex of Stressed Mice
}

\author{
Michihisa Tohda, ${ }^{*}$ Salin Mingmalairak, Yukihisa Murakami, and Kinzo Matsumoto \\ Division of Medicinal Pharmacology, Institute of Natural Medicine, University of Toyama; 2630 Sugitani, Toyama \\ 930-0194, Japan. Received August 11, 2009; accepted September 7, 2009; published online October 6, 2009
}

\begin{abstract}
We previously reported that long-term treatment with some antidepressants at low concentrations upregulates BCL2/adenovirus E1B 19-kDa-interacting protein 3 (BNIP3) mRNA expression in NG108-15 cells without causing cell damage, suggesting that BNIP3 is a candidate of intrinsic depressive disorder-related factor(s). In this study, to clarify the physiologic functions of BNIP3, we investigated whether BNIP3 is actually related to the depressive condition in the brain using learned helplessness (LH) mice, an animal model of depression. Based on the score of escape failure, an index of depression degree, stressed animals were divided into groups with LH and without depressive-like symptoms (i.e., non-depressed phenotype, non-LH). The score of escape failure of the LH group was decreased after $14 \mathrm{~d}$ of treatment with imipramine in a dose-dependent manner. BNIP3 mRNA expression was enhanced in both the LH and non-LH groups. Imipramine treatment at 5 and $20 \mathrm{mg} / \mathrm{kg} / \mathrm{d}$ enhanced BNIP3 mRNA expression only in the LH group but not in non-LH group or non-stressed group. These results raise the possibility that $B N I P 3$ acts as an antistress factor in the brain.
\end{abstract}

Key words depressive disorder; gene expression; learned helplessness; BCL2/adenovirus E1B 19-kDa-interacting protein 3; imipramine

The investigation of the pathogenetic molecular mecha$\operatorname{nism}(\mathrm{s})$ of diseases is an indispensable approach not only for a thorough understanding of diseases of interest but also for the development of innovative therapeutic treatments. It has been believed that monoamine transporters are major target molecules for the chemotherapy of depression and antidepressant drug development. ${ }^{1,2)}$ However, it has not been confirmed whether the monoamine hypothesis is sufficient to explain the pathogenesis of depression and/or antidepressant action of drugs. An understanding of the detailed molecular mechanisms of depressive disorders indispensable for radical treatment will provide novel viewpoints on therapeutic strategies and drugs for Alzheimer's and Parkinson's diseases.

Recent studies have demonstrated that hypoxia or stroke insult induces upregulation of BCL2/adenovirus E1B 19$\mathrm{kDa}$-interacting protein 3 (BNIP3) expression in the brain which is implicated in neuronal cell death. ${ }^{3-5)}$ However, physiologic/pathophysiologic role of this protein in the brain remains to be clarified. Recently, Tohda et al. ${ }^{6}$ have reported that treatment with imipramine, mianserin, and milnacipran, but not fluoxetine, causes upregulation of BNIP3 mRNA expression in NG108-15 cells without inducing apoptotic cell damage and that upregulation of BNIP3 mRNA expression in the cell line is also induced by Hochu-ekki-to, a Kampo prescription used to treat such conditions as general fatigue, poor appetite, and low-grade fever, as an adjunct to treating debilitation resulting from chronic diseases ${ }^{7)}$ and exhibits antidepressant-like activity in the forced swimming test. ${ }^{8}$ These findings raised the possibility that BNIP3 may be a marker related to depressive disorders or to a pharmacologic action commonly caused by antidepressant drugs. BNIP3 is a proapoptotic protein classified as a member of the Bcl-2 family due to limited sequence homology to the Bcl-2 homology 3 (BH3) domain and to the C-terminal transmembrane domain. ${ }^{9}{ }^{910}$ However, it remains unclear whether antidepressant drug treatment causes upregulation of BNIP3 mRNA expres- sion in vivo in the brain or whether the changes in BNIP3 mRNA expression in the brain are relevant to depressive disorders

The learned-helplessness (LH) behavior of experimental animals caused by inescapable footshocks is one behavioral phenotype relevant to depression. ${ }^{11,12)}$ Since this behavior can be ameliorated by antidepressants, LH animals have been widely used for studying the pathophysiology of depression and the actions of antidepressants. ${ }^{13,14)}$ Therefore, in this study, expression changes of BNIP3 mRNA and the effect of the antidepressant imipramine on its expression in the brain were examined using this LH mice.

\section{MATERIALS AND METHODS}

Animals Ten-week-old male ICR mice (Japan SLC Inc., Shizuoka, Japan) weighing 38-40 g were housed in groups of 8 per cage under standard conditions: $25 \pm 1^{\circ} \mathrm{C}$ ambient temperature; $65 \pm 5 \%$ relative humidity; 12 -h light/dark cycle (lights on from 07:30 to 19:30). They had ad libitum access to food and water and were allowed to acclimatize to these housing conditions for 1 week prior to the experiments. The care and use of the animals were in accordance with the Guiding Principles for the Care and Use of Animals in the Field of Physiological Science of the Physiological Society of Japan and the Institutional Animal Use and Care Committee of the University of Toyama, and the study was designed to minimize pain and the number of animals used.

Learned Helplessness The LH mouse model of depression was prepared as previously described. ${ }^{15)}$ Briefly, the animals were individually placed in a plexiglas chamber $\left(28 \times 16 \times 10 \mathrm{~cm}^{3}\right)$ with a stainless steel grid floor (MSC-001, Muromachi Kikai, Tokyo, Japan) attached to a shock generator (SGS-003/T, Muromachi Kikai) and exposed to 60 inescapable footshocks $(0.16 \mathrm{~mA}, 15$-s duration, 45 -s average interval) once a day for 3 consecutive days. Control animals 
were placed in identical chambers for the same period without receiving shocks. The escape performances of the animals were tested in the two-way shuttle box at 1 and $15 \mathrm{~d}$ (days 4 and 18, respectively) after the third day of exposure to inescapable footshocks. Animals were subjected to 30 avoidance trials with 15 -s average intervals. In each trial, a tone $(80 \mathrm{~dB})$ and light signal was first presented for maximum of 3-s. If no avoidance response occurred during the 3s period, an electric shock $(0.16 \mathrm{~mA})$ was delivered to the animals for a maximum of 3-s with the signals. Animals could escape footshocks by moving to the other side of the box (escape response), and the signals and the shock terminated on the response. Escape failures were counted as a measure of LH.

Imipramine Administration Imipramine hydrochloride (Nacalai Tesque, Kyoto, Japan) was dissolved in saline $(0.9 \%$ $\mathrm{w} / \mathrm{v} \mathrm{NaCl})$ and two doses $(5,20 \mathrm{mg} / \mathrm{kg})$ were administered intraperitoneally in a constant volume of $10 \mathrm{ml} / \mathrm{kg}$ body weight. Imipramine was administered once daily for $14 \mathrm{~d}$, starting on day 5 . On day 18 , the mice were tested for escape ability under escapable shock conditions $60 \mathrm{~min}$ after the administration of imipramine or saline.

RNA Preparation and Semiquantitative Reverse Transcription-Polymerase Chain Reaction (RT-PCR) The mice were killed $1 \mathrm{~h}$ after the behavioral test. Total RNA was extracted from the frontal cortex using on RNeasy Mini Kit (Qiagen, Tokyo, Japan) according to the manufacturer's protocol. First-strand cDNA was synthesized using Reverscript III (Wako, Tokyo, Japan) from $1 \mu \mathrm{g}$ of total RNA and $0.1 \mu \mathrm{M}$ oligo(dT) primer in a $20-\mu \mathrm{l}$ mixture. PCR was conducted in $10-\mu \mathrm{l}$ of reaction mixtures containing $0.5 \mu \mathrm{l}$ of first-stand cDNA mixture, $0.5 \mu \mathrm{M}$ sense and antisense primers, $0.25 \mathrm{~mm}$ deoxynucleotide triphosphates (dNTPs), and 2 units of Taq polymerase (Promega, Madison, WI, U.S.A.) containing $2.5 \mathrm{mM} \mathrm{MgCl}_{2}$. Thermocycling was performed using the following protocol: (1) $94^{\circ} \mathrm{C}$ for $2 \mathrm{~min}$, designated cycles of $94^{\circ} \mathrm{C}$ for $30 \mathrm{~s}$, (2) $57^{\circ} \mathrm{C}$ for $1 \mathrm{~min}$, and $72^{\circ} \mathrm{C}$ for $1 \mathrm{~min}$, and then (3) $72{ }^{\circ} \mathrm{C}$ for $5 \mathrm{~min}$ followed by cooling at $4{ }^{\circ} \mathrm{C}$. PCR products were electrophoresed on $6 \%$ polyacrylamide gel and then stained with ethidium bromide. The bands were visualized under UV light and quantified using Densitograph ${ }^{\circledR}$ ver. 4.0 (Atto, Tokyo, Japan). The specific primers for BNIP3 were 5'-GAA CTG CAC TTC AGC AAT GG-3' (forward) and 5'-GCC AGC AGA TGA GAC AGT AA-3' (backward). The PCR cycle number for BNIP3 mRNA was 24 and the estimated product size was $464 \mathrm{bp}$.

Statistical Analysis The results are expressed as mean \pm S.E.M. Two-way repeated-measure analysis of variance (ANOVA), followed by the Student-Newman-Keuls test, was used for the statistical evaluation of behavioral data obtained from the avoidance test. Data obtained from semiquantitative RT-PCR analysis was evaluated using Student's $t$-test or one-way ANOVA followed by the Student-Newman-Keuls test.

\section{RESULTS}

Consistent with previous reports, ${ }^{16,17)}$ the animals exposed to inescapable footshock stress exhibited different extents of LH behavior in the test conducted on day 4 (after footshock exposure) and because of different susceptibility to the stress, those exposed to inescapable footshocks consisted of animals with and without depression-like symptoms. In this study, the mice that received footshocks to induce $\mathrm{LH}$ behavior could be divided into two groups based on "failure scores" recorded on day 4, i.e., the LH group with high failure scores no less than 10 and the non-LH group with low failure scores no more than 5 (Table 1). The LH animals with high failure scores of $\geq 10$ were judged to be depressive.

The animals with high failure scores (LH group) on day 4 were then randomly divided into 3 groups. Each group received intraperitoneal (i.p.) injection of 5 or $20 \mathrm{mg} / \mathrm{kg}$ imipramine or saline once daily for $14 \mathrm{~d}$ from day 5. Twoway repeated-measure ANOVA revealed significant interaction between imipramine $(20 \mathrm{mg} / \mathrm{kg} / \mathrm{d})$ treatment and testing $\left[F_{\text {treatment } \times \text { test }}(1,4)=8.459, p<0.05\right]$. No difference in failure scores on day 4 was found between the 2 groups $[p=0.959]$, but the LH group treated with imipramine $(20 \mathrm{mg} / \mathrm{kg}$, i.p.) for $14 \mathrm{~d}$ had a significantly reduced failure score in the $\mathrm{LH}$ test conducted on day 18 than the saline-treated LH group [ $p=0.023]$ (Table 2).

We evaluated the expression level of BNIP3 mRNA in the frontal cortex of each animal group $1 \mathrm{~h}$ after inescapable footshock exposure on day 4. Semiquantitative RT/PCR analysis revealed that the expression level of BNIP3 mRNA in the frontal cortex tended to be higher in the animals exposed to inescapable footshock than in stress-naïve control animals. However, no significant difference in the expression level was found between the LH and non-LH groups on day $4[t=-0.432, d f=15, p=0.672]$ (Fig. 1).

The expression levels of BNIP3 mRNA in the LH and

Table 1. Phenotypic Difference in Learned Helpless (LH) Behavior in Mice

\begin{tabular}{lc}
\hline \hline Group & Escape failure scores \\
\hline Control & $1.83 \pm 0.87$ \\
LH & $13.63 \pm 0.93$ \\
Non-LH & $2.22 \pm 0.55$
\end{tabular}

The number of escape failure in the LH test was recorded at day 4 after inescapable footshock exposure. Data are expressed as mean \pm S.E.M. ( $n=6-9$ per group).

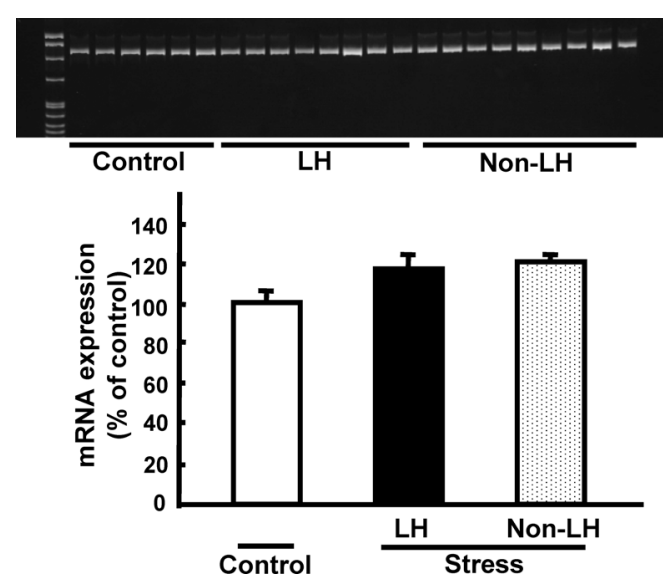

Fig. 1. Changes in the Levels of BNIP3 in the Frontal Cortex of Mice Subjected to Inescapable Footshock

Frontal cortexes were sampled $1 \mathrm{~h}$ after the LH test, and the levels of BNIP3 were determined using semiquantitative RT/PCR. Data are expressed as mean \pm S.E.M. and expressed as a percentage of the control group ( $n=6-9$ per group). No significant differences were detected (Student's $t$-test). 
Table 2. Effects of Imipramine on Inescapable Footshock-Induced Escape Failure in the LH Test

\begin{tabular}{lcc}
\hline \hline \multirow{2}{c}{ Group } & \multicolumn{2}{c}{ Escape failure scores } \\
\cline { 2 - 3 } & $\begin{array}{c}\text { Day 4 } \\
\text { (before treatment) }\end{array}$ & $\begin{array}{c}\text { Day 18 } \\
\text { (after treatment) }\end{array}$ \\
\hline Vehicle-treated footshock-naïve control & $3.60 \pm 1.44$ & $1.00 \pm 0.45$ \\
Vehicle-treated non-LH & $1.80 \pm 0.58$ & $4.60 \pm 2.20$ \\
Vehicle-treated LH & $17.20 \pm 2.80$ & $22.60 \pm 1.10$ \\
$5 \mathrm{mg} / \mathrm{kg}$ Imipramine-treated LH & $17.40 \pm 1.60$ & $18.20 \pm 2.00$ \\
$20 \mathrm{mg} / \mathrm{kg}$ Imipramine-treated LH & $17.40 \pm 1.70$ & $12.60 \pm 4.20^{*}$ \\
\hline
\end{tabular}

The LH test was performed on days 4 and 18. The animals exposed to inescapable footshock were divided into the $\mathrm{LH}$ and non- $\mathrm{LH}$ groups based on escape failure scores recorded on day 4 . The non-LH animals received vehicle for $14 \mathrm{~d}$ from day 5 . The $\mathrm{LH}$ animals were subdivided into three groups. Each group received either saline or imipramine $(5,20 \mathrm{mg} / \mathrm{kg}$, i.p.) once daily for $14 \mathrm{~d}$ (from day 5 to day 18 ). On day 18 , the LH test was conducted $60 \mathrm{~min}$ after the last drug administration. Data are expressed as mean \pm S.E.M. ( $n=5$ per group). $* p<0.05$ vs. vehicle-treated LH group (two-way ANOVA followed by the Student-Newman-Keuls test).

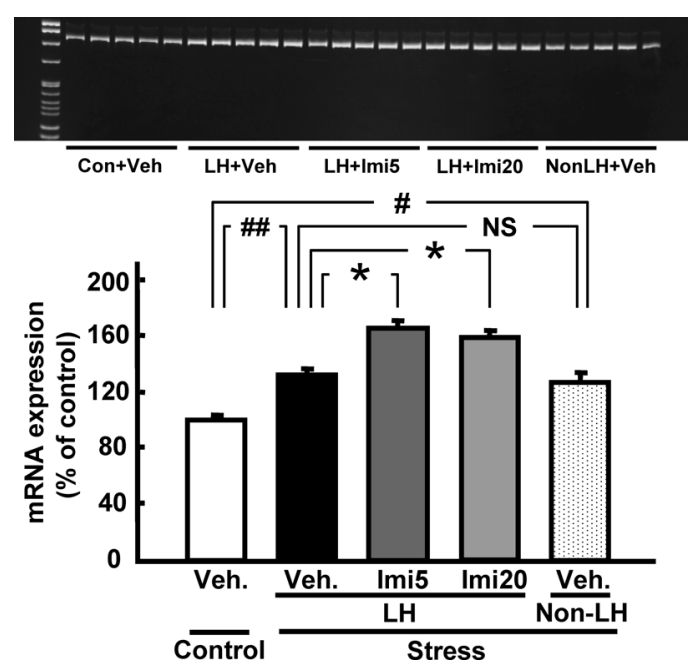

Fig. 2. Effects of Imipramine on BNIP3 mRNA Levels in the Frontal Cortex of LH and Non-LH Mice

Imipramine (Imi, $5,20 \mathrm{mg} / \mathrm{kg}$, i.p.) was administered once daily for $14 \mathrm{~d}$. The $\mathrm{LH}$ test was performed $60 \mathrm{~min}$ after the last drug administration. Frontal cortexes were sampled $1 \mathrm{~h}$ after the LH test, and BNIP3 mRNA levels were determined using semiquantitative RT/PCR. Data are expressed as mean \pm S.E.M. and expressed as a percentage of the values obtained from the control group ( $n=5$ per group). ${ }^{\#} p<0.05$, \# $p<0.01 v s$. the vehicle-treated control group (Student's $t$-test), $* p<0.05$ vs. vehicle-treated LH group (oneway ANOVA followed by the Student-Newman-Keuls test). NS, not significant.

\section{A}
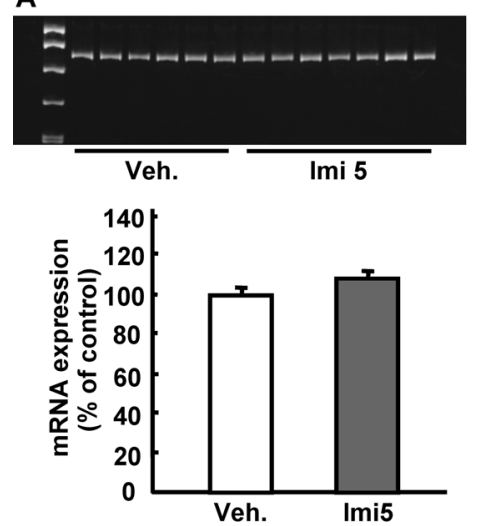

non-LH groups on day 18 were significantly higher than that in the control group [LH vs. control, $t=-5.436, d f=8$, $p<0.001$, non-LH vs. control, $t=-3.285, d f=8, p=0.011]$ (Fig. 2). No clear relationship was observed between the failure score in the LH test and the BNIP3 mRNA expression level in the brain $[r=0.503]$. However, the expression level of BNIP3 mRNA in 5 and $20 \mathrm{mg} / \mathrm{kg}$ imipramine-treated $\mathrm{LH}$ mice was elevated compared with the level in vehicle-treated LH animals $[F(2,12)=11.245, p=0.002]$ (Fig. 2). A similar result was obtained using the real-time PCR method (data not shown), although the variations in the values were high for the limitations of the precision of the real-time PCR method when the expression differences were small (less than 2-fold). Post-hoc analysis showed that imipramine treatment significantly increased the expression levels of BNIP3 expression (imipramine $5 \mathrm{mg} / \mathrm{kg} / \mathrm{d} \quad v s$. vehicle, $p<0.05$; imipramine $20 \mathrm{mg} / \mathrm{kg} / \mathrm{d}$ vs. vehicle, $p<0.05)$. In contrast, imipramine $(5 \mathrm{mg} / \mathrm{kg} / \mathrm{d}$, i.p.) treatment of normal animals $[t=-1.500, \quad d f=11, \quad p=0.162]$ and non-LH animals $[t=-0.511, d f=10, p=0.620]$ for $14 \mathrm{~d}$ failed to affect the expression level of BNIP3 mRNA in the brain (Fig. 3).

\section{DISCUSSION}

We have previously reported that Hochu-ekki-to, a Wakanyaku medicine with an antidepressant-like action, and typical antidepressants enhance the expression of BNIP3 mRNA in the cultured cell line NG108-15, suggesting that BNIP3 is a candidate for intrinsic factors related to antidepressive effects. ${ }^{6)}$ The present study used an LH mouse model of depression to demonstrate that BNIP3 mRNA expression is enhanced under stress conditions and may be involved in imipramine-induced amelioration of the depressive state in the LH test.

Lines of evidence have confirmed the validity of the $\mathrm{LH}$ animal model of depression, and this model is widely used to assess antidepressive actions of many compounds and drugs. ${ }^{11-14)}$ Variable predispositions such as different susceptibility to stressful stimuli are also reportedly involved in the pathogenesis of depression. ${ }^{16,17)}$ Therefore in this experimental protocol, the mice received moderate current stimula-

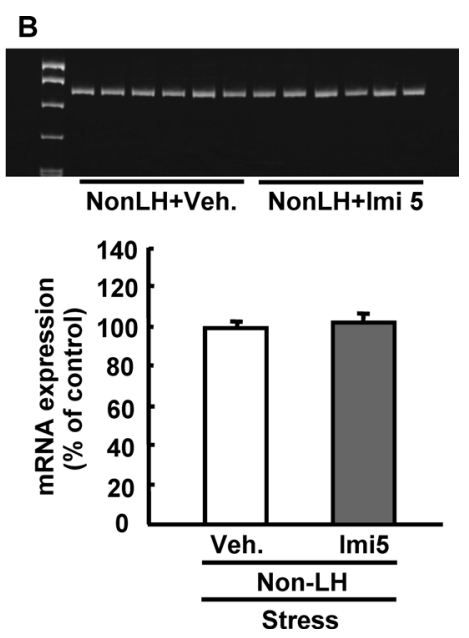

Fig. 3. Effects of Imipramine on BNIP3 mRNA Levels in the Frontal Cortex of Normal Footshock-Naïve Mice (A) and Non-LH Mice (B)

Imipramine (Imi, $5 \mathrm{mg} / \mathrm{kg}$, i.p.) was administered once daily for $14 \mathrm{~d}$. The frontal cortexes were sampled $2 \mathrm{~h}$ after the last drug administration, and the levels of BNIP $3 \mathrm{mRNA}$ were determined using semiquantitative RT/PCR. Data are expressed as mean \pm S.E.M. and expressed as a percentage of the values obtained from the vehicle control group $(n=6-$ 7 per group). No significant differences were detected (Student's $t$-test). 
tion to induce different degrees of LH behavior. This protocol provided animal groups with different susceptibility to inescapable footshock stimulation: a non-LH group with low failure scores like footshock-naïve control animals and LH group with high failure scores in the LH test. The administration of imipramine $(20 \mathrm{mg} / \mathrm{kg}$, i.p.) for $14 \mathrm{~d}$ to the $\mathrm{LH}$ animals reduced the increased escape failure score compared with the vehicle control group. These findings indicate that the $\mathrm{LH}$ animals that responded to imipramine treatment can be considered to have a predisposition to depressive disorder.

Interestingly, in the present study, we found that the administration of imipramine significantly elevated BNIP3 mRNA expression in the brains of LH animals without affecting the level in the footshock-naïve animals. Tohda et al. ${ }^{6}$ have demonstrated in a previous in vitro study that the culture of NG108-15 cells with antidepressant drugs resulted in upregulation of BNIP3 mRNA expression without inducing cell death and suggested that BNIP3 plays a physiologic role(s) other than proapoptotic function and may be an endogenous factor relevant to depression and/or antidepressant activity. The present results indicate that imipramine treatment is capable of causing upregulation of BNIP3 mRNA expression not only in cultured cells in vitro but also in the brain in vivo in mice with a depressive-like condition, such as LH mice, although this was not observed in the normal brain. These data suggest that a change in the BNIP3 mRNA expression level may be relevant to the physiologic response to stressful physical stimulation but not to the behavioral phenotype of depression since imipramine treatment failed to upregulate BNIP3 mRNA expression in the brains of footshock-naïve animals. It is likely that the changes in the BNIP3 mRNA expression level in the brain of LH and nonLH mice are relevant to the physiologic response to stressful physical stimulation and/or retrieval of fear memory conditioned by a tone and light signal but not to despair-like behavior or LH in mice, a behavioral phenotype of depression in rodents. It is of interest that the administration of imipramine $5 \mathrm{mg} / \mathrm{kg} / \mathrm{d}$ for $14 \mathrm{~d}$ significantly elevated BNIP3 mRNA in the brains of LH mice without affecting the expression in the footshock-naïve mice. These findings may point to the following hypothesis: although imipramine can increase BNIP3 mRNA expression at a lower concentration than the concentration that induces improvement of the phenotype, the increased BNIP3 is not sufficient to achieve the antidepressive effects alone. Other factors that induce the expression or are activated by higher concentrations of imipramine may also be involved in the therapeutic effects and should be interested to identified in future studies.

Evidence indicates that BNIP3 is involved in cell death via disruption of mitochondrial function ${ }^{18,19)}$ and regulation of proapoptotic activities. ${ }^{9}$ However, there are conflicting reports on the biological/physiologic roles of BNIP3. BNIP3 is required to initiate the autophagic cell survival process in response to hypoxic stress in both normal and tumor cells. ${ }^{20)}$ Moreover, recent studies have suggested that BNIP3 functions not only as a prodeath protein but also as a cell survival factor (see Drzyzga et al. ${ }^{21)}$ for review). Considering the previous data ${ }^{6)}$ showing that treatment with some antidepressant drugs caused elevation of BNIP3 mRNA expression in NG108-15 cells, the present results allow us to infer that both elevation of BNIP3 mRNA expression in respons to stressful stimulation and imipramine-induced potentiation of the elevation under stressful conditions may be linked to a compensatory response to the brain damage caused by inescapable stressful stimulation. Since BNIP3 is constitutively expressed even in the unstressed mouse brain, it is unlikely that the function of BNIP3 is related only to cell death/survival. Sandau and $\mathrm{Handa}^{3)}$ reported the localization and developmental ontogeny of BNIP3 mRNA in the rat brain and that BNIP3 is widely distributed throughout the whole brain by postnatal day 7, although it is located mostly in the hippocampus in the adult brain. Furthermore, BNIP3 mRNA levels were found to peak on postnatal day 6.5 in the cortex and hippocampus. ${ }^{3)}$ Neuronal networks in the brain are generally formed within 1 week after birth. ${ }^{22)}$ From these findings, we speculate that BNIP3 has functional roles in synapse formation in the later stage. As an antistress reaction factor, BNIP3 may play a role in the maintenance and/or reformation of synapses in the brain, and antidepressants may assist the function of BNIP3 by enhancing its expression.

In conclusion, these results raise the possibility that BNIP3 may act as an antistress factor in the brain. Imipramine exhibits upregulatory effects on BNIP3 mRNA expression only under depressive conditions in vivo in the brain depending on exposure of animals to repeated stressful physical stimulation and/or conditioned fear memory. The relationship between depressive disorder and mitochondrial function has been noted. Mitochondrial dysfunction has been seen in some depressive patients. ${ }^{23-25)}$ A depressive model animal with mutation of the mitochondrial DNA is also based on this viewpoint. ${ }^{26)}$ As described above, the physiologic function of BNIP-3 is thought to be expressed after binding to the mitochondrial membrane. The results of the present study suggest that BNIP-3 mRNA expression is enhanced to compete with harmful effects in mitochondria induced by stress as an antistress factor. Further experiments using primary cultured cells, animal brains, and cloned cell lines are needed to clarify the physiologic significance of the enhanced expression of BNIP3 mRNA by antidepressants.

\section{REFERENCES}

1) Millan M. J., Eur. J. Pharmacol., 500, $371-384$ (2004).

2) Wong M. L., Licinio J., Nat. Rev. Neurosci., 2, 343-351 (2001).

3) Sandau U. S., Handa R. J., Neuroscience, 144, 482-494 (2007).

4) Schmidt-Kastner R., Aguirre-Chen C., Kietzmann T., Saul I., Busto R., Ginsberg M. D., Brain Res., 1001, 133-142 (2004).

5) Zhang Z., Yang X., Zhang S., Ma X., Kong J., Stroke, 38, 1606-1613 (2007).

6) Tohda M., Hayashi H., Sukma M., Tanaka K., Neurosci. Res., 62, 1-8 (2008).

7) Terasawa K., "Japanese-Oriental Medicine: Insight from Clinical Case,” KK Standard McIntyre, Tokyo, 1993.

8) Watanabe H., Matsumoto K., Satoh T., Ohta H., Matsuda H., J. Med. Pharm. Soc. Wakan-Yaku, 7, 99-107 (1990).

9) Boyd J. M., Malstrom S., Subramanian T., Venkateah L. K., Schaeper U., Elangovan B., D’Sa-Eipper C., Chinnadurai G., Cell, 79, 341-351 (1994).

10) Yasuda M., Theodorakis P., Subramanian T., Chinnadurai G., J. Biol. Chem., 273, 12415-12421 (1998).

11) Nestler E. J., Barrot M., DiLeone R. J., Eisch, A. J., Gold S. J., Monteggia L. M., Neuron, 34, 13-25 (2002).

12) Willner P., Adv. Biochem. Psychopharmacol., 49, 19-41 (1995).

13) Chourbaji S., Zacher C., Sanchis-Segura C., Dormann C., Vollmayr B., Gass P., Brain Res. Protoc., 16, 70-78 (2005).

14) Takamori K., Yoshida S., Okuyama S., Pharmacology, 63, 147-153 
(2001).

15) Li S., Wang C., Wang M.-W., Murakami Y., Matsumoto K., Pharmacol. Biochem. Behav., 83, 186-193 (2006).

16) Kram M. L., Kramer G. L., Steciuk M., Ronan P. J., Petty F., Neuroscience, 38, 193-198 (2000).

17) Vollmayr B., Simonis C., Weber S., Gass P., Henn F., Biol. Psychiatry, 54, 1035-1040 (2003).

18) Kubasiak L. A., Hernandez O. M., Bishopric N. H., Webster K. A., Proc. Natl. Acad. Sci. U.S.A., 99, 12825-12830 (2002).

19) Vande Velde C., Cizeau J., Dubik D., Alimonti J., Brown T., Israels S., Hakem R., Greenberg A. H., Mol. Cell. Biol., 20, 5454-5468 (2000).

20) Bellot G., Garcia-Medina R., Gounon P., Chiche J., Roux D., Pouysségur J., Mazure N. M., Mol. Cell. Biol., 29, 2570-2581 (2009).
21) Drzyzga L. R., Marcinowska A., Obuchowicz E., Brain Res. Bull., 79, 248-257 (2009).

22) Blue M. E., Parnavelas J. G., J. Neurocytol., 12, 599—616 (1983).

23) Kato T., Kunugi H., Nanko S., Kato N., J. Affect. Disord., 62, 151164 (2001)

24) Munakata K., Tanaka M., Mori K., Washizuka S., Yoneda M., Tajima O., Akiyama T., Nanko S., Kunugi H., Tadokoro K., Ozaki N., Inada T., Sakamoto K., Fukunaga T., Iijima Y., Iwata N., Tatsumi M., Yamada K., Yoshikawa T., Kato T., Genomics, 84, 1041-1050 (2004).

25) Munakata K., Iwamoto K., Bundo M., Kato T., Biol. Psychiatry, 57, 525-532 (2005).

26) Kasahara T., Kubota M., Miyauchi T., Noda Y., Mouri A., Nabeshima T., Kato T., Mol. Psychiatry, 11, 577-593 (2006). 